\title{
Sleep bruxism and anxiety level in children
}

Marcelo Tomás de OLIVEIRA(a) Sandra Teixeira BITTENCOURT(a) Karina MARCON ${ }^{(a)}$ Samia DESTRO(a) Jefferson Ricardo PEREIRA ${ }^{(b)}$

(a) Universidade do Sul de Santa Catarina UNISUL, School of Dentistry, Department of Dental Materials, Tubarão, SC, Brazil.

(b) Universidade do Sul de Santa Catarina UNISUL, School of Dentistry, Department of Prosthodontics, Tubarão, SC, Brazil.

Declaration of Interests: The authors certify that they have no commercial or associative interest that represents a conflict of interest in connection with the manuscript.

\section{Corresponding Author:}

Jefferson Ricardo Pereira

E-mail: jeffripe@rocketmail.com

DOI: 10.1590/1807-3107BOR-2015.vol29.0024

Submitted: Apr 02, 2014

Accepted for publication: Oct 15, 2014

Last revision: Dec 05, 2014
Abstract: This study evaluated the association of level of anxiety in children with and without sleep bruxism (SB). The study was performed with 84 six- to eigth-years-old children, divided into two groups: with bruxism (BG) and without bruxism (CG). Following the criteria purposed by American Academy of Sleep Medicine (AASM) to determine $\mathrm{SB}$, the presence of tooth wear has been verified through clinical examinations, and the parents have answered a questionnaire about their children's behavior and habits. Additionally, the State-Trait Anxiety Inventory for Children (STAIC) was applied to parents of the selected patients. Data analysis revealed a statistical significant difference between the groups (Student's t-test, $p=0.0136$ ). Based on the results, anxiety assessment revealed that children with bruxism have reached higher levels in the STAIC scale than the non-bruxism group. Therefore, it indicates a direct relationship between the presence of anxiety disorder and the onset of bruxism in children.

Keywords: Bruxism; Anxiety; Child.

\section{Introduction}

Traditionally, bruxism is the term used to define daytime and nighttime parafunctional activities, which include the acts of grinding, rubbing, tapping, and clenching. Recently, bruxism with concomitant tooth grinding was reclassified as a sleep-related oral-motor movement disorder. ${ }^{1}$ Some authors also distinguish between diurnal and nocturnal, or sleep bruxism (SB). The difference between the two types is that the latter has a totally involuntary motion. ${ }^{2,3}$

Sleep disorders that have been reported to be concomitant with bruxism include obstructive sleep apnea, parasomnias, restless legs syndrome, oral mandibular myoclonus, and rapid eye movement behavior disorders. ${ }^{3,4,5}$ Despite the controversy around the exact area of the nervous system where bruxism is triggered, i.e., peripheral or central, the main consequences of bruxism can be observed in the oral-dental area. Such consequences may include tooth destruction, dental work failure, temporomandibular joint and jaw muscle pain or jaw movement limitation, and temporal headache. . $^{3,4,5,6}$

The diagnosis and clinical assessment of bruxism is a complex process. What differentiates patients who were initially diagnosed with bruxism from others who were not diagnosed with the disorder despite exhibiting some degree of nocturnal parafunctional activity is the duration and intensity of muscular contractions, which are dramatically altered in patients suffering from bruxism. ${ }^{6}$ 
The etiology of bruxism is complex, multifactorial and, therefore, difficult to identify. ${ }^{78}$ The most frequently mentioned condition is emotional, with stress and anxiety being considered risk factors that are associated with occlusal problems. ${ }^{3,9}$

Anxiety in children is a common occurrence in clinical pediatric psychiatry. Its prevalence is $2.5 \%$ to $5 \%$ in the general population and $10.6 \%$ to $24 \%$ in the clinical population. ${ }^{6}$ In recent years, a large number of studies aimed to better identify and understand the characteristics of this symptom in the pediatric population. Different from the adult population, the symptoms were related to anxiety change according to the phases of child development, which often makes identification difficult. ${ }^{10,11}$

The aim of this study was to measure and compare the level of anxiety between children who were diagnosed with bruxism and children who were not bruxers. The null hypothesis is that anxiety is not an important risk factor for sleep bruxism in children.

\section{Methodology}

This study was approved by a human research ethics committee at Universidade do Sul de Santa Catarina - UNISUL (protocol no. 11.216.4.02.III). After the legal guardian signed the informed consent, the sample included, per convenience, children of both genders aged 6 to 8 years who were divided into two groups: the bruxism group - BG (the first 42 children diagnosed with bruxism) and the control group - CG (the first 42 children who were not diagnosed with bruxism). To standardize the sample, only children in the mixed dentition stage participated in this study. All exams were performed by two examiners whose previews calibrated $(\mathrm{K}=0.73)$.

The anamnesis was performed in the clinic of the Dentistry School of Universidade do Sul de Santa Catarina by one examiner who is an expert in psychological treatment. The children's parents were interviewed because the children were judged to be too young to answer the questions reliably. After the anamnesis, the children who were taking medications or who had associated epileptic activity or other medical, mental, or behavioral disorders were excluded from this study. In addition, the indispensable condition required to confirm the diagnosis included a guard- ian's report of nocturnal clenching and grinding sounds. During the anamnesis conducted with the parents, they were asked to answer whether they had heard their child clenching or grinding their teeth two or more times per week.

To determine sleep bruxism, we applied the minimal criteria proposed by the American Academy of Sleep Medicine (AASM). ${ }^{1}$ The methodology follows this reasoning: Diagnostic Criteria - Sleep Bruxism (code-306.8) minimal criteria: A plus B.

A. The patient has a complaint of tooth-grinding or tooth-clenching during sleep.

B. One or more of the following occurs:

1. Abnormal wear of the teeth;

2. Sounds associated with the bruxism;

3. Jaw muscle discomfort.

Only anterior teeth were evaluated to measure wear. ${ }^{12}$ To standardize the dental wear patterns, the following criteria proposed by Bernal and Tsantsouris ${ }^{13}$ were used: (1) Dental wear of the enamel only; (2) Dental wear of the enamel and dentin; (3) Dental wear of up to $1 / 3$ of the length of the crown; and (4) Dental wear more than $1 / 3$ of the length of the crown. Children who had grade 2 or higher were considered to possess positive diagnostic criteria.

After the anamnesis and clinical examination, the trait anxiety scale for children was applied by their parents, as proposed by Bouden, ${ }_{10}^{10}$ and translated from French to Portuguese by Assumpção Jr and Resch. ${ }^{12}$

To verify the perception of parents about their children, a question was added to the anamnesis form in which the parents were asked to choose those characteristics that they deemed descriptive of the patient's behavior (i.e., shy, nervous, anxious, fearful, and aggressive). There was no minimum or maximum limit of these features to be mentioned; only yes or no questions were included in the anamnesis.

Chi-square (with Yates correction), Mann-Whitney and unpaired Student's t-tests were used for statistical analysis. The level of significance for all tests was set at 0.05 .

\section{Results}

Forty-five girls and 39 boys were observed. The mean age for the girls was $7.1 \pm 0.5$ years (mean \pm standard deviation), and that for the boys 
was $7.3 \pm 0.4$ years. No statistically significant difference in the age of participants was found ( $p=0.6688$ ).

Table 1 shows how parents observed the behavior of their children. The BG group showed a significantly higher proportion of children characterized by their parents as anxious $(p=0.001)$ and nervous $(p=0.043)$. However, no significant difference was observed among timidity $(p=0.056)$, shyness $(p=0.366)$ and aggressiveness $(p=0.155)$.

In the trait anxiety scale approach, the levels established for the responses were determined by considering each participant and performing a comparison of the groups. Statistical analysis of the data revealed a statistically significant difference (Student's t-test $p=0.0136$ ): the summation of responses for anxiety was greater in children with bruxism than in the control group. Figure shows the profile of the response sums.

Table 2 shows the median of the responses to each of the 34 questions on the trait anxiety scale for children obtained in both study groups. Questions 1, 6 and 11 showed statistically significant differences between the groups.

\section{Discussion}

Despite the recently proposed distinction between diurnal and nocturnal bruxism, the etiology of this functional disturbance seems to be strongly influenced by psychological factors. ${ }^{3,4,5}$ Specifically, anxiety and distress were encountered to a higher degree in patients who were diagnosed with bruxism compared with non-bruxers. ${ }^{14}$ Confirming the finding of the study quoted above, the present study demonstrated comparable results by applying the trait anxiety scale, and bruxing children showed higher anxiety levels than did the non-bruxing group (Figure).

Anxiety in childhood is a frequent occurrence. ${ }^{10}$ However, it is most likely underdiagnosed because of diverse symptomatology, particularly according to the different phases of development. The tools available to evaluate anxiety seem to imply problems of reliability and validity. Because of those limitations, in this study, we selected an interview that was validated for use with parents. ${ }^{12,13}$ It is important to note that scales alone are not capable of making a diagnosis of anxi- ety. However, in this study, the scale served to make comparisons between the groups and indicate that symptoms may be more prominent in one group than another. Additionally, the data obtained directly from the parents, distinct from the anxiety scale, showed that the sleep bruxism group presented a significantly higher proportion of children who were characterized as anxious and nervous (Table 1).

Anxiety is described as an unpleasant emotion characterized by worry, tension, and fear, which are felt occasionally and to varying degrees. ${ }^{12,14}$ It is suggested that childhood anxiety can occur because of its presence in the surrounding environment and is influenced by social factors such as homework and household chores. ${ }^{15,16}$

When analyzing each item on the trait anxiety scale, it was found that the children with bruxism

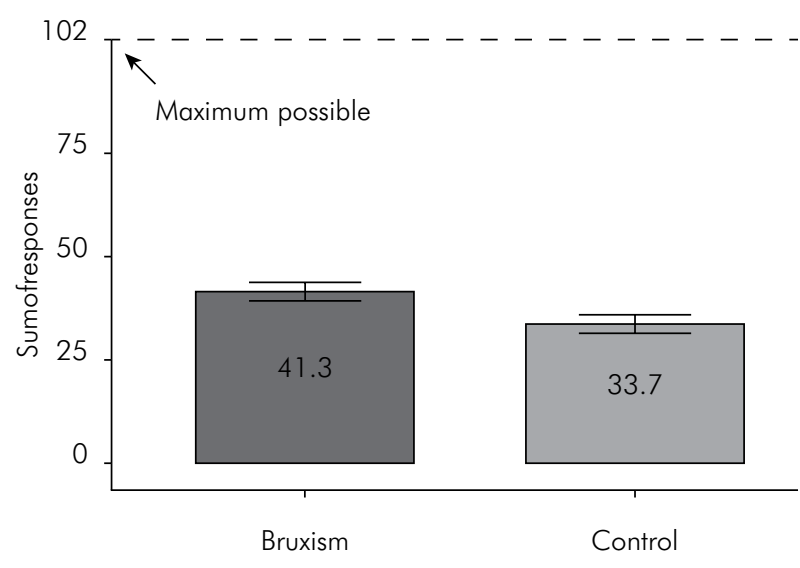

Figure. Graphic showing mean ( \pm SEM) of the sum of the response levels to the trait anxiety scale for children. Maximum possible $=$ level 3 in response to all 34 questions (total scale $=102)$. (Student's T test $p=0.0136$ )

Table 1. Relative frequency (n.\%) of psychological factors as observed by parents/guardians.

\begin{tabular}{lccc}
\hline & Bruxism $(n=42)$ & Control $(n=42)$ & $p$-value* \\
\hline Anxious & $35(83.3 \%)$ & $20(47.6 \%)$ & 0.0013 \\
Nervous & $21(50 \%)$ & $11(26.2 \%)$ & 0.0432 \\
Fearful & $18(42.9 \%)$ & $13(31 \%)$ & 0.3658 \\
Aggressive & $7(16.7 \%)$ & $2(4.8 \%)$ & 0.1555 \\
Timid & $7(16.7 \%)$ & $14(33.3 \%)$ & 0.0564 \\
\hline
\end{tabular}

* Chi-square test. 
were more restless, had greater concerns about school, and presented a greater amount of spontaneous complaints of forgetfulness and memory gaps than did the non-bruxing individuals, which suggests an association between these factors and sleep bruxism (Table 2). This finding is in agreement with previous studies, which suggested that children whose parents insist on good grades, homework and household chores can develop emotional defense mechanisms, allowing for the onset of parafunctional habits such as teeth grinding and clenching. ${ }^{10,16}$

Finally, a multidisciplinary approach is essential in determining the etiology of bruxism and developing a correct diagnosis to avoid both under and overtreatment. Clinicians should be aware of this scarcity of evidence regarding the management of sleep bruxism and anxiety. There is an enormous

Table 2. Median ( $1^{\text {st }}$ and $3^{\text {rd }}$ quartiles) of responses (levels) to questions of trait anxiety scale for children for each study group.

\begin{tabular}{|c|c|c|c|}
\hline Trait Anxiety Scale for Children & Bruxism & Control & $p^{*}$ \\
\hline 1 - Has a tendency to show restless & $2[1-3]$ & $1[1-2]$ & $0.0074 *$ \\
\hline 2 - Has a tendency to worry & $1[0-2]$ & $1[0-1]$ & 0.2341 \\
\hline 3 - Has a tendency to have stomach pains & $1[0-1]$ & $1[0-1]$ & 1.0000 \\
\hline 4 - Has a tendency to avoid people who are not familiar & $1[0-1.75]$ & $1[0-1]$ & 0.8305 \\
\hline 5 - Has a tendency to ask much about the daily facts & $2[2-3]$ & $2[1-3]$ & 0.2764 \\
\hline 6 - Has a tendency to worry about school & $2[1-3]$ & $1[1-2]$ & $0.0097^{*}$ \\
\hline 7 - Complains of headaches & $1[1-2]$ & $1[0-1]$ & 0.4004 \\
\hline 8 - Complains of several types of pain & $1[0-1]$ & $1[0-1]$ & 0.0692 \\
\hline 9 - Tends to be irritable, angry, complaining about everything & $2[1-2]$ & $1[0.25-2]$ & 0.0701 \\
\hline 10 - Tends to ask a lot about unusual or surprising issues & $2[1-3]$ & $2[1-2]$ & 0.0877 \\
\hline 11 - Complains spontaneously about forgetfulness or memory gaps & $1[0-1.75]$ & $0[0-1]$ & $0.0068^{*}$ \\
\hline 12 - Is concerned with what others think about him/her & $1.5[1-2]$ & $1[0.25-2]$ & 0.3385 \\
\hline 13 - Refuses to be alone or is afraid of loneliness & $1[0-2]$ & $1[0-2]$ & 0.6653 \\
\hline 14 - Quickly abandons initiated tasks & $1[0.25-2]$ & $1[0-2]$ & 0.5022 \\
\hline 15 - Cries easily & $2[1-2]$ & $1[1-2]$ & 0.2503 \\
\hline 16 - Searches security situations & $2[1-2.75]$ & $2[1-2]$ & 0.3317 \\
\hline 17 - Is afraid of the dark & $1[0-2]$ & $0.5[0-2]$ & 0.3806 \\
\hline 18 - Is sensitive to criticism & $2[1-2]$ & $2[1-2]$ & 0.1248 \\
\hline 19 - Shows systematic refusal and whims & $1[1-2]$ & $1[1-3]$ & 0.5387 \\
\hline 20 Is doubtful of his/her value and success & $1[0-1]$ & $0[0-1]$ & 0.2008 \\
\hline 21 - States that poor performance in school is justified by forgetfulness or memory problems & $1[0-1]$ & $0[0-1]$ & 0.6132 \\
\hline 22 - Is unstable, agitated, overexcited & $2[1-3]$ & $1[0-2]$ & 0.2254 \\
\hline 23 - Has a tendency to present digestive problems (nausea, vomiting, diarrhea) & $0[0-1]$ & $0[0-1]$ & 0.6002 \\
\hline 24 - Has difficulty feeding (capricious appetite, food denial) & $0.5[0-2]$ & $1[0.25-2]$ & 0.1272 \\
\hline 25 - Worries about having bad performance or to harm others & $2[0-2]$ & $1[0-2]$ & 0.3207 \\
\hline 26 - Tends to be distracted or has difficulty concentrating & $1[1-2]$ & $1[1-2]$ & 0.6482 \\
\hline 27 - Bites nails & $1[0-3]$ & $1[0-2.75]$ & 0.8615 \\
\hline 28 - Complains of chest tightness or difficulty breathing & $0[0-1]$ & $0[0-0.75]$ & 0.1602 \\
\hline 29 - Has trouble sleeping & $0[0-1.75]$ & $0[0-1]$ & 0.6939 \\
\hline 30 - Complains of difficulty swallowing & $0[0-0]$ & $0[0-0]$ & 0.6741 \\
\hline 31 - Startles with noise & $1[0-1]$ & $0[0-1]$ & 0.2448 \\
\hline 32 - Has frequent nightmares & $1[0-1]$ & $1[0-1]$ & 0.8756 \\
\hline 33 - Complains that the heart beats too strongly & $0[0-1]$ & $0[0-0]$ & 0.2170 \\
\hline 34 - Tends to make nervous movements & $0[0-1]$ & $0[0-0]$ & 0.1340 \\
\hline
\end{tabular}


need for well-designed studies on the management of bruxism in children, particularly studies that can evaluate the effects of dental, psychological, physiotherapeutic, surgical and other therapies compared with prognostic therapies.

\section{References}

1. American Academy of Sleep Medicine (AASM). International classification of sleep disorders: diagnostic and coding manual. 2nd ed. Westchester (IL): American Academy of Sleep Medicine; 2005.

2. Lavigne GJ, Khoury S, AbeS, Yamaguchi T, Raphael K. Bruxism physiology and pathology: an overview for clinicians. J Oral Rehabil. 2008 Jul;35(7):476-94.

3. Kato TJ, Lavigne GJ. Sleep bruxism: a sleep-related movement disorder. Sleep Med Clin. 2010 Mar;5(1):9-35.

4. Bader G, Lavigne G. Sleep bruxism; an overview of an oromandibular sleep movement disorder: review article. Sleep Med Rev. 2000 Feb;4(1):27-43.

5. Restrepo C, Gomez S, Manrique R. Treatment of bruxism in children: a systematic review. Quintessence Int. 2009 Nov-Dec;40(10):849-55.

6. Knutson GA. Vectored upper cervical, manipulation for chronic sleep bruxism, headache, and cervical spine pain in a child. J Manipulative Physiol Ther. 2003 Jul-Aug;26(6):E16.

7. Svensson P, Jadidi F, Arima T, Baad-Hansen L, Sessle BJ. Relationships between craniofacial pain and bruxism. J Oral Rehabil. 2008 Jul;35(7):524-47.

8. Johansson A, Haraldson T, Omar R, Killiaridis SGE, Carlsson GE. A system for assessing the severity and progression of occlusal tooth wear. J Oral Rehabil. 1993 Mar;20(2):125-31.
The limitations of this study include the fact that Assumpção Jr and Resch ${ }^{12}$ validated their test of anxiety in a different age group than that of the children examined in this article. It would therefore be helpful to conduct more studies selecting children of different ages.

9. Hachmann A, Martins EA, Araujo FB, Nunes R. Efficacy of the nocturnal bite plate in the control of bruxism for 3 to 5 year old children. J Clin Pediatr Dent. 1999 Fall;24(1):9-15.

10. Bouden A, Halayem MB, Fakhfakh R. Preliminary validation study of infantile trait-anxiety scale. Neuropsychiatr Enfance Adolesc. 2002 Feb;50(1):25-30. French.

11. Rios D, Magalhães AC, Honório HM, Buzalaf MA, Lauris JR, Machado MA. The prevalence of deciduous tooth wear in six-year-old children and its relationship with potential explanatory factors. Oral Health Prev Dent. 2007;5(3):167-71.

12. Assumpção Jr FB, Resch CR. Trait anxiety evaluation scale validation - a study of sensibility and specifity. Braz J Psych. 2006;10:19-25.

13. Bernal M, Tsamtsouris A. Signs and symptoms of temporomandibular joint dysfunction in 3 to 5 year old children. J Pedod. 1986 Winter;10(2):127-40.

14. Barbosa TS, Miyakoda LS, Pocztaruk RL, Rocha CP, Gavião MB. Temporomandibular disorders and bruxism in childhood and adolescence: review of the literature. Int J Pediatr Otorhinolaryngol. 2008 Mar;72(3):299-314.

15. Vanderas AP, Menenakou M, Kouimtzis T, Papagiannoulis L. Urinary catecholamine levels and bruxism in children. J Oral Rehabil. 1999 Feb;26(2): 103-10.

16. Antonio AG, Pierro VS, Maia LC. Bruxism in children: a warning sign for psychological problems. J Can Dent Assoc. 2006 Mar;72(2):155-60. 